rains will then carry it to the slight depth necessary The roots. importance with leference to the utilization by the nlant of the nutritive matter introduced into the soil.
The more plentiful and the more regular the dissemina

The slag, on account of its specific weight, is readily cattered, but in our region the northwest wind is at the right moment. The use of fertilizer distributers
may therefore be advised, but it is better, I think, to may therefore be advised, but it is better, I think, to mix the slag with fine earth, which may be scattered
in a slight wind still too rough for sowing the slag.
This mixture causes a more regular spreading; the This mixture causes a more regular spreading; the
workmen cannot scatter large parcels at once. The employment of the distributers is also useful when there are large quantities of slag to scatter, to prevent corrosion of the hand of the workman.

The slag should be mixed with other fertilizers, ammonium sulphate in the mixture, for ammonia would be immediately disengaged. The proportions to be employed depend on the richness of the soil and on soil is lacking in phosphoric acid, no inconvenience will result from applying the slag profusely.

\section{THE TANREC}

Tre Berlin Menagerie, according to the Illustrirte Zeitung. numbers among its collections of rare aniinsectivorous animal which has inherited from its ancestors certain characteristics that are not to be
found in any of the species of hedgehog. One of these hereditary characteristics is the bristling coat of the animal, which marks the transition stage from hair
to spine. True bristles or spines in the tanrec are to spine. True loristles or spines in the tanlec are
found only on the occiput. on the neck. and on the found only on the occiput. on the neck, and on the
sides of the body, where they are longest. The cover-

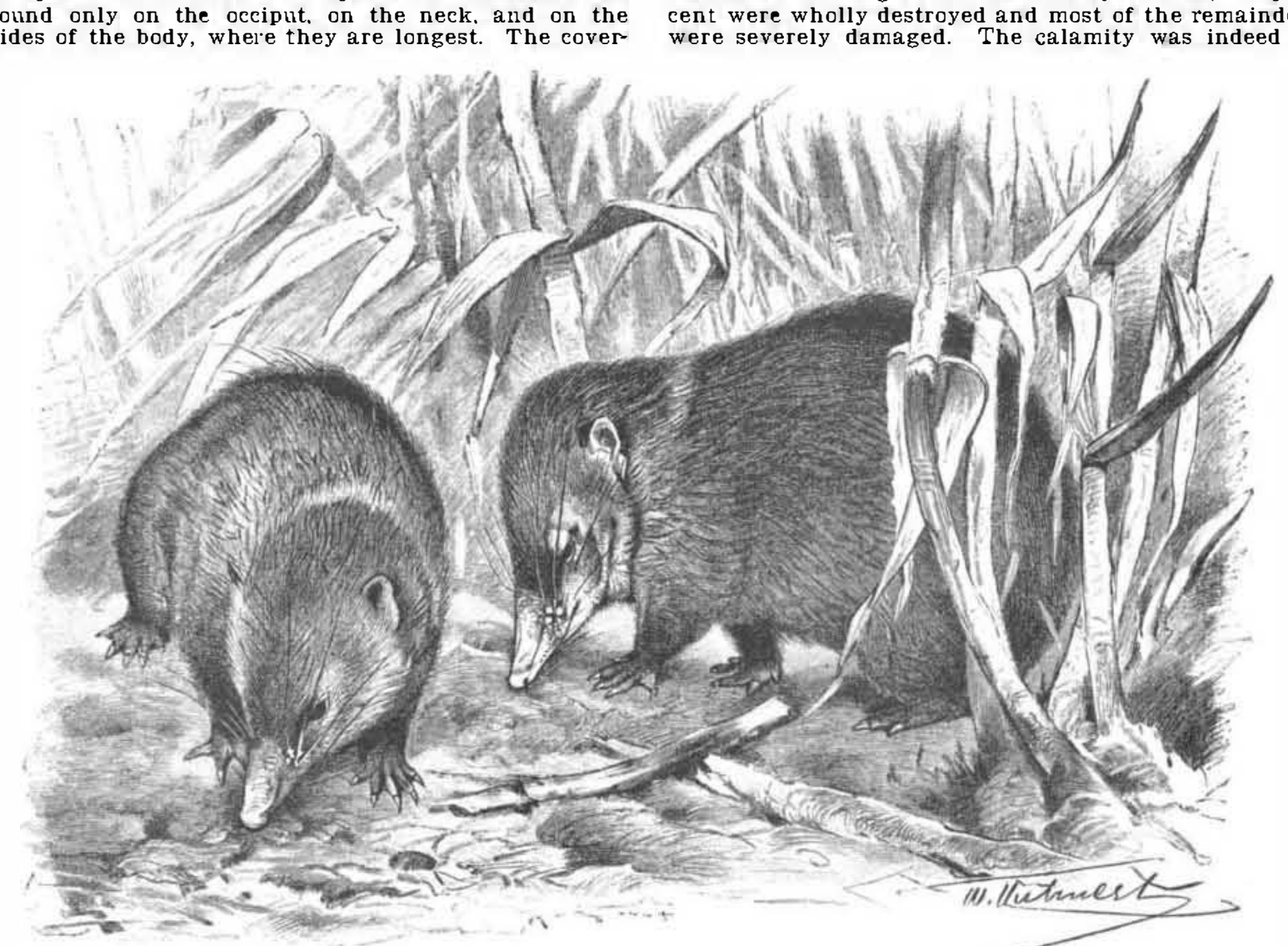

THE MADAGASCAR TANREC.

ing on the back of the animal consists of a bristle-like formation, while the abdomen and legs are covered by hair. The tanrec lives in the dense underbrush and
terns of its native island. As a skillful borer the tanrec forms passages and galleries in the earth, which may cover animal is its arr The tanrec thus sleeps during the time in which it is difficult to obtain nourishment. So delicate is the the natives of Madagascar.

\section{ICELAND'S EARTHQUAKES.}

Nu part of the world excepting Japan and a few other Asiatic islands is visited so frequently by earth quakes as Iceland. This great volcanic rock is shaken by about seventy.five severe earthquakes in a century.
The most violent effects are often found in the unin. The most violent effects are often found in the unin. habited parts of the country which comprise most of
the island. of course, in these cases, there is not why comparatively little is heard of the earthquakes of Iceland. Until the last great series of shocks occurred the competent to collect accurate data and to describe them adequately. These earthquakes occurred five ycars ago in the western, or inhabited, part of the
country and a great deal of damage resulted though country and a great deal of damage resulted though
the loss of life was very small. They continued the loss of life was very small. They continued
through August and September, 1896. Later that fall famous as the scientific explorer of Ireland collected by correspondence much information from person who lived in the disturbed area. In the summer of 1897 he traveled all through the region affected in
order to study all phases of the catastrophe and to collect evidence from many eye-witnesses. He wrote an exhaustive report which was published in the Ice
landic language in 1899, making a book of 200 pages $A$ condensed account of these earthquakes has jus been published loy Dr. Thoroddsen in German, and th
few facts here given are taken from this long report.
While the earthquakes were felt throughout the fourth of the island the most severe disturbance occurred in a triangular area in the southwest part not far from the sea and covering a district about
cso square miles in extent. Outside of this area and extending further inland strong shocks were felt over affects main regions of disturbance and including all the western part of the island; so that the total land area
affected was about 21,000 square miles. As it is probable that an equally large area of the sea foor was
disturbed it is supposed that the movements extended with greater or less intensity through the rocks cover with greater or less intensity through the rocks cover-
ing an area of about 40.000 square miles or more than affected was a little larger than this State. Reykjavik, the capital and chief town, was in the region of least If these earthquakes had occurred in any very popu-
lous land with high houses and large cities the destruction of life hould haves and large cities the destruc land the danger is lessened by the peculiar type of consists of small and low houses, the inner walls made of wood while the outer walls and roof are of warm grass thatch, a great protection against the winter cold. Stone houses are built in considerable
numbers in the larger towns, but they are very dangernumbers in the larger towns, but they are very dangerdiately when assaulted by such terrific shocks as those of 1896 . Wooden houses usually hold together until their occupants have time to get out of them. This is the reason why the loss of life is very small though damaged.

-ut of a total of 4,430 dwelling houses and 5,739 severely shaken, 17 pe were severely damaged. The calamity was indeed a were found. them six to nine miles in length filled with wate and lookerl like long. thread like lakes, some of them

completely draining small lakes and swamps which they happened to cross. many mineral springs and geysers. New ones came existence. On the night of September $5 \cdot 6$ a new geyser, amid the most deafening noise, suddenly made
itself manifest by an outburst of water, steam and itself manifest by an outburst of water, steam and
stones that were shot coo feet into the air. Its force only twelve to sixteen feet above the surface. A year later the basin it had formed had a length of fifty. five feet and a breadth of thirty feet and was flled
with clear hot water. The renowned Strokkur geyser. which came into action at the time of the great earthearthouate period of 1396 , and a year later its basin earthquake period of 1896 , and a year later its basin gained its power and at last accounts had frequent periods of violent outbursts, throwing water to a great height. The hot spring at Biskupstungur, which merefrom twenty-five to thirty-five feet in the air. Many cold springs and wells underwent great changes, old As is usual in Iceland the earthquakes began in the east and the movement was toward the west. The volcanoes Hecla, Kalta and Eyjafjallajökull were completely passive during and after the earthquake periods. orizinated is an area of subsidence. Steep mountain slopes form the boundary between the highland and
the low plain. Dr. Thorodsen says the probability is the low plain. Dr. Thoroddsen says the probability is a line of breakage in the rocks. The earthquakes in the plain, probably caused by breakages and slip.
pings among the deep-seated rocks under the plain. do not send their earth waves among the mountains
of the interior, for the spreading of these waves to the highlands is interpreted by deep-lying crevasses caused by these the rocks. But the tremendous jar caused by these subterranean movements is felt far extend over a large part of the island.-New York Sun.

NEW RESEARCHES $\bullet N$ THE ALL $\bullet S$ G G $\bullet$ SILVER, AND OTHER MATTER F@UND IN THE EGYPTIAN TOMBS.* By M. Berthelot.

Is pursuing my researches on the metals of antiguity, I have been led to make a special examina-
tion of the samples of pure or alloyed gold proceeding from Egyptian tombs, and particularly of fine leaves used in the gilding of mummies and other objects. I lish some probable relations between the chemical processes of their manufacture, in the cases where this date is established by the archroologists, so as to be able in other cases to ascend from the composition revealed by chemical analysis, either to the unknown Rate of manufacture or to the mineralogical origin of
the samples. To arrive at conclusions of value, the determinations must be repeated sufficiently.

I have already published some results of this kind in my studies on the Dahchour excavations and on director of Egyptian Antiquities. He has had the
kindness to send me various new samples, and I will give the rasults of my examination.
A. I. Simall frayments of gold. from the tomb of King Horus of ahchour. XIIIth dynasty. - This sam-
ple weighs 0.0082 gramme. It is a beaten metallic leaf (about a thousandth of a millimeter thick). The them being of a pure golden yellow, the other reddish and quite dark in places. This last tint is distributed
unequally. It does not appear attributable to the metal itself, but to an extremely thin coating of
organic material, proceeding without doubt from conorganic material, proceeding without doubt from con-
tact with the mummy. The weight is not appreciable on so small a sample. The material burns when the its normal color. The analysis has furnished in 100 parts-Gold, 92.7; Ther, 4.6; other matters. 2.4 per cent.
B. Two little packiets of metallic lewes designated
as gold, silver. or electrum, coming from tomb of

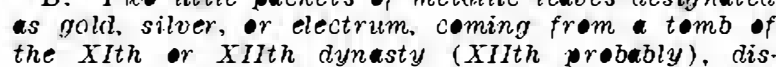
the XIth or XIth dynasty (XIIth robably), dis
corered at Bercheh and belonging to a certain
Tahoutinaknout.-I have divided these leaves accord ing to their appearance into four groups for analysis. ing to their appearance into four groups for analysis. thick, on the a verage. Variable thickness, from 0.001 $\mathrm{mm}$. to $\mathbf{0 . 0 0 1 5} \mathrm{mm}$. and $\mathbf{0 . 0 0 2 5} \mathrm{mm}$. Gold, 74.52
silver, 14.94; patina and other matter, 10.54 .
III. Yellow gold of packet $N \bullet$. 1.-Gold, 80.1 ; silver,

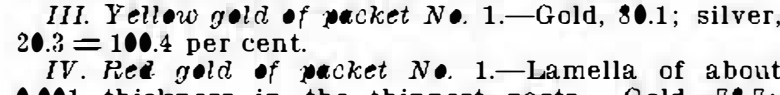
0.001 thickness in the thinnest parts. Gold, 78.7 silver, $20.9=99.6$ per cent.
V. Yellow gold of packet No. 2.-Lamella about 0.001
$\mathrm{~mm}$. in thickness. Gold, $77.3 ;$ silver, $22.2=99.5$ per cent. Deeper red gold of packet $N \bullet$. 2.-The gold is tarnished on one side by an organic matter, like that of sample I., which gives it the appearance of being plated. This matter is destroyed when the gold leaf
is heated to the red. Thickness about $0.001 \mathrm{~mm}$. in is heated to the red. Thickness about $0.001 \mathrm{~mm}$. in
the thinnest parts. Gold, 78.2; silver, $21.1=99.3$ ner cen

It will be remarked that the gold leaves have a
thickness of about one to two thousandths of a mil limeter, but without regularity. The samples III. IV., V., VI., have nearly the same composition, consisting of an artifial alloy or of a native mineral
which contains four parts of gold and one part of which contains four parts of gord an made the dis
silver. The difference in tint, which tinct existence of gold and of electrim thought of contact or by the emanations of the mummy. contact or by the emanations of the mummy.
Sample II. is composec of silver mixed with one fifth of gold. an alloy, or rather a native ore.
Lilse the Dahchour treasure, none of these samples 
is of pure gold; the ratio of grold to silver is five to one; the gold leaves of the VIth and of the XIIth dynasties contain only 3.2 to 4.5 hundredths of silver, the Horus tomb. This confirms the preceding remarks on the composition of Egyptian gold.

C. Other objects.- I will give the results observed on some other objects coming from the same tomb. VIJ. Solid material. reputed perfume.-This is a
fragile resin, of a brownish yellow, compact, with fragile resin, of a brownish yellow, compact, with
conchoidal fracture. Heated, it behaves like colophony, having a similar odor. having a similar odor.
VIII. Two round whitish bowls, having the appear-
ance of a petrified material, afterward agglomerated by desiccation. The tomb contained about thirty of them. Diameter. $22 \mathrm{~mm}$.

These bowls were regarded by the persons who found them as perfume. I have ascertained that they do not contain organic matter. They are in reality porphyrized, rich in silica, and associated with a little calcium carbonate, which must have served as cement. to comprehend the motives which have led to the placing of such articles in a tomb.

IX. M. Maspero has added to his parcel a little red metallic lamella, about $60 \mathrm{~mm}$. long, 6 to $7 \mathrm{~mm}$. wide
It is almost pure copper, like the most ancient statuettes of Gondeah and of the palace of the King OurNina.

\section{THE STEAM TURBINE.}

THE problem of thermodynamic energy conversion, so far as the reciprocating steam engine is concerned, than a century ago. Ideal in its complex was more tion and revolutionary in its applications and achievements, the steam engine, originating with Newcomen and perfected by Watt, is, however, very far from perfect as a heat engine, and there is little prospect that future improvements will bring this type of heat motor much closer to the ideal. This assumption is to some degree borne out by the fact that the improvebeen merenical and days of Janh naturally have increased its efficiency, the steam engine of to-day in its ingenious and complex perfection, thermodynamically presents little improvement over that of Watt.

The conversion of heat energy by means of the steam engine is accomplished by allowing steam to expand behind the piston, not utilizing its kinetic been brought out in a state of great perfection and The steam turbine in principle is not new, being the first heat motor recorded in the history of steam engineering, as far back as 120 B. C., when Hero of Alexandria, then the center of the civilized world, describes an apparatus for utilizing heat energy. This apparatus, a reaction turbine, consisted of a
spherical vessel mounted upon trunnions through which steam was admitted, to finally issue from openwhich steam was admitted, to finally issue fries later,
ings tangential to the sphere. Many centurien in 1629, the Italian, Giovanni Branca, brought out the impact turbine, employing a jet of steam to impinge upon the vanes or blades of a wheel. This latter, familiar to us in the hydraulic motors of the Pelton type, exhibits in general principle the characteristic
features embodied in the present-day De Laval steam features embodied in the present-day De Laval steam

Thus we see as early as 1629 the introduction of fect form and not impact turbine, although of imperall attempts at perfection along these lines have, until a comparatively this was probably owing, however, to the interest aroused in the success of Newcomen in 1705, and later by Watt and his followers, in perfecting the recipro-

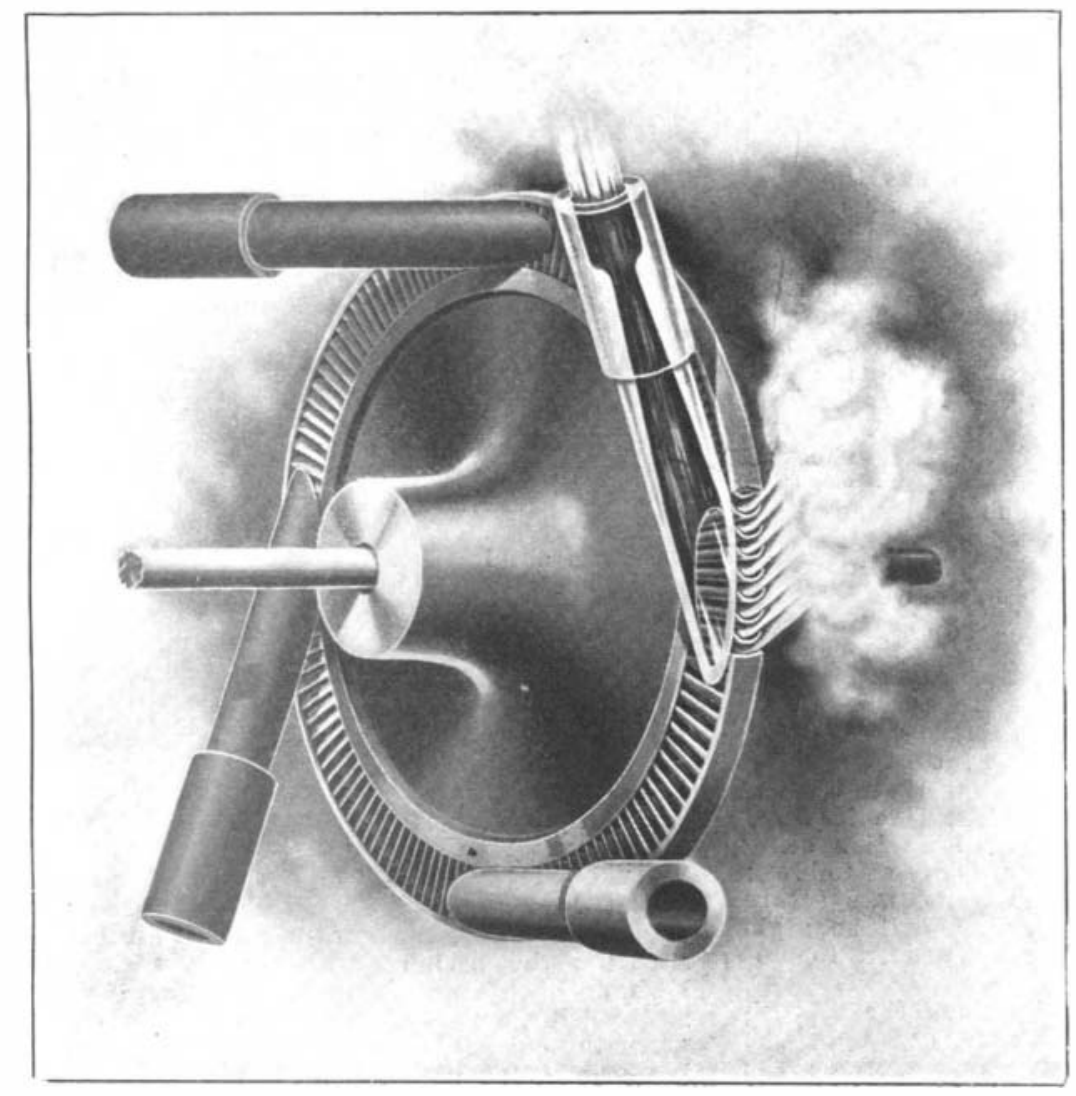

Fig. 2.-THE 1)E LAVAL TURBINE WHEEL AND NOZZLES.

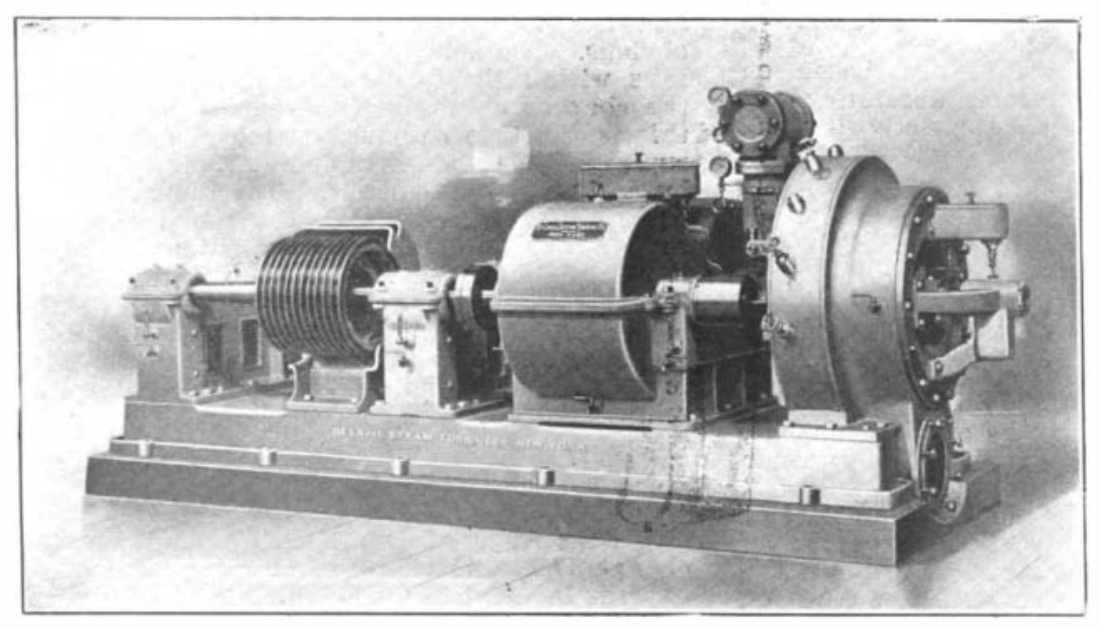

FI(i. 2.--De LAVAI، STEAM TURBINE, 300 H. P.

ered in places with verdigris. I have found in 100 I do not know to what object it previously belonged.

$X$. In examining the gold leaves, alloyed with onefourth of silver, included in $B$, I found three little rings, perfectly alike and regular, which have occupied my attention. One of them weighed $13.9 \mathrm{mgr}$. It constituted a regular tore. Its outer diameter was equa and consequently the diameter of the interior circum ference, $1.55 \mathrm{~mm}$.

This ring was made of devitrified glass, withou tin or any other metal in its interior, but covered with a thin greenish patina, containing a trace of

The existence of such objects raised new questions. In fact, these little rings must have hung on some beads, because they have not been connected by soldering but strung on a linen or metal thread. manufacture must have presented some difficulty, be cause of the thirness of the rings $(0.75 \mathrm{~mm}$.) $\mathrm{com}$ pared with their diameter $(3.05 \mathrm{~mm}$. $)$

I will add to the preceding analysis that of a sample of Chaldean metal sent by M. Henzey. It is from the our era The filings detached contain: Copper, 92.9, sand, 0.2 ; oxidized potash, 8.9 (without other metal).

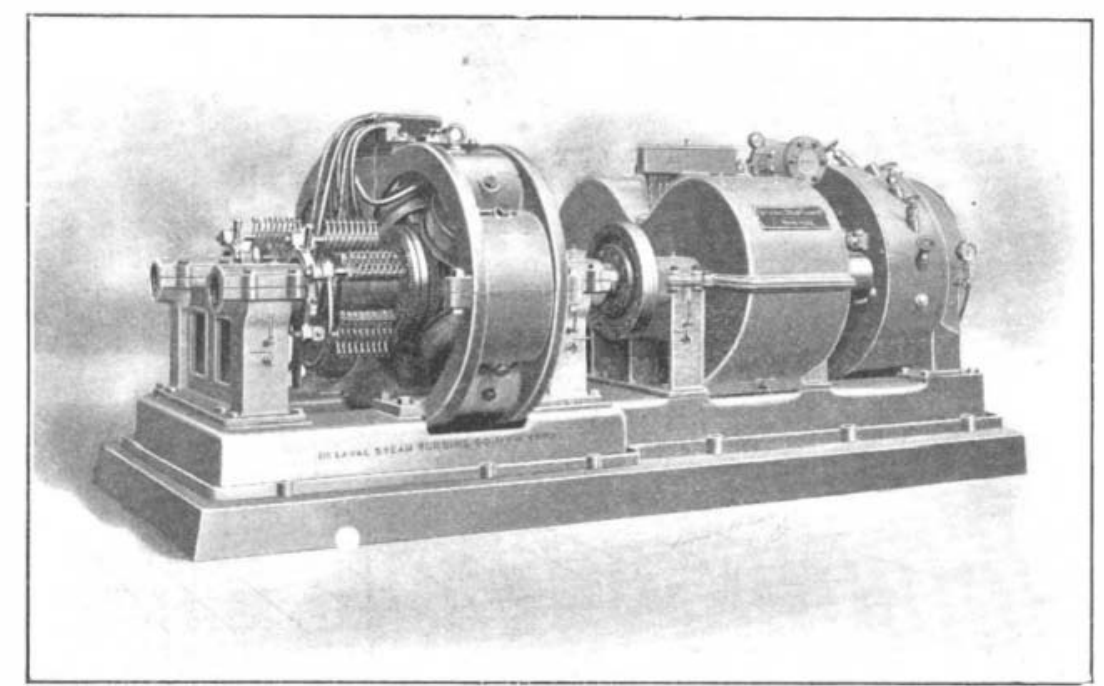

FIf. :-DF LAVAL S'TEAH TURBINE DINAMU ZUU H. P.

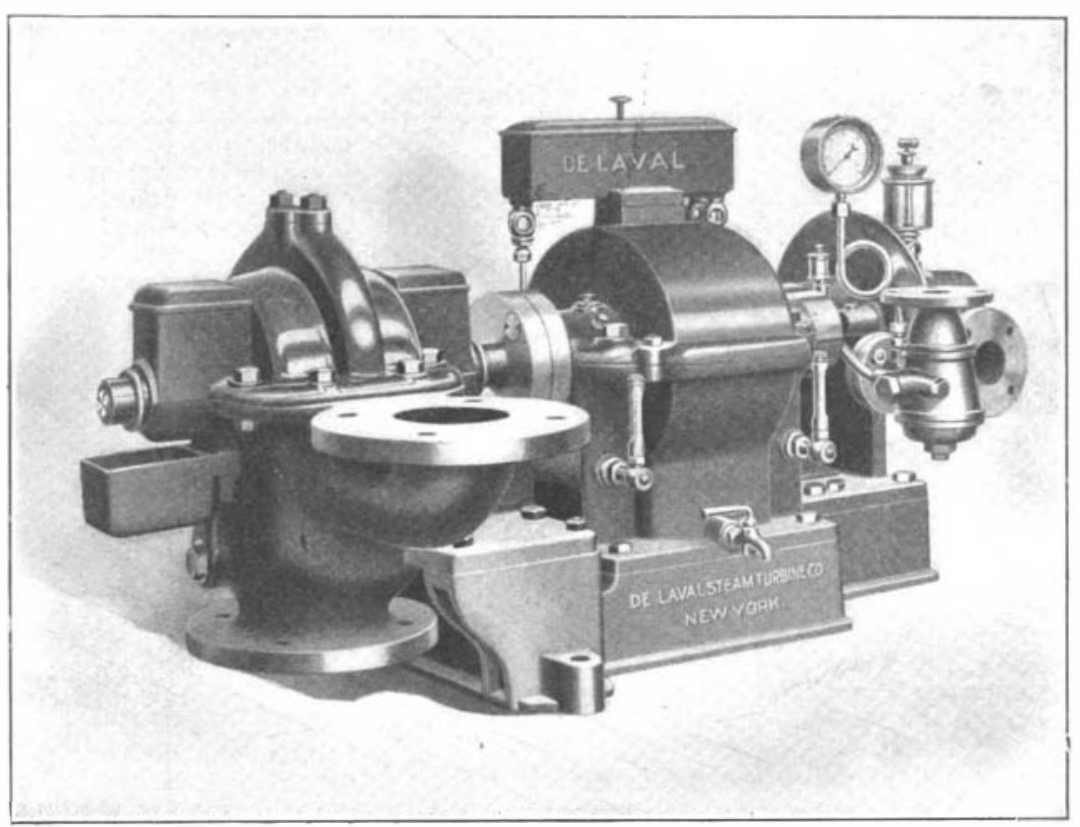

FI(. 4.-15 H. P. STEAH TURBINE PUMT

ing with its pressure. The ideal efficiency of this process, and in fact the solution of the problem of not cycle.

This means that for the highest efficiency obtainable the steam should be expanded from maximum to minimum pressure and temperature, and furthermore thi expansion should be adiabatic, which, as is well known in practical operation with the steam engine, is no and never can be accomplished. The reason for this, now so well known, need not here be mentioned. oughly understood and the defects of and the improbability of further than mechanically improving the steam engine were realized, engineers and inventors with more or less success, set about devising mean for mechanical utilization of heat energy by method promising a closer approach to the ideal than is possiThe activity arong this sine of resear The activity along this line of research has been vices having any pretense to rivalry with the the decating engine has been the rotary steam engine. This type of engine, successful in obviating the defects due to reciprocating motion, has, however, in other re spects proven far inferior to the type it has sought to replace; it is especially wasteful of steam, and can
Laval, characterized by the great simplicity of its sion prod and the directness of its energy converideal conditions which can never be attained with the steam engine. That the steam turbine, which now more than rivals the steam engine, should have been known at such an early date and yet should have been so long delayed in its perfection in a practical form, may seem astonishing. This is, however, not remarkahad for en kn the high efis is, hower of the steam turbine times, a practical steam turbine could not well early been produced for want of materials and tools of such tial to the construction of a successful steam turbine as are the principles involved. The steam engine, less exacting in this respect, has been the natural forerunner, producing the favorable conditions that have enabled us to weld another link to the

In 1883 De Laval made the first successful steam irect connection with the shaft this country by the De Laval Separator Company. This, his first steam turbine, a reaction wheel, was, however. soon replaced by one of the Branca type and of the results attained Prof. Thurston says. The result was an astonishing efficiency in many cases of 